\title{
Fronteiras, portas e muralhas na cidadela de Micenas
}

\author{
Gustavo J. P. Peixoto*
}

PEIXOTO, G.J.P. Fronteiras, portas e muralhas na cidadela de Micenas. R. Museu Arq. Etn., 35: 135-151, 2020.

Resumo: Este artigo explora o conceito de fronteira no mundo antigo utilizando como estudo de caso as fronteiras materiais e simbólicas produzidas pelas muralhas e portas da cidadela de Micenas entre os séculos XIV a.C. e XIII a.C. Este estudo tem o objetivo de identificar o modo como as elites micênicas materializavam seu discurso de poder no espaço por meio da construção de muralhas ciclópicas monumentais, da criação de marcos simbólicos como a porta dos leões e da disposição proposital e estratégica de edifícios que se encontram entre a porta principal e o palácio do soberano micênico. Para compreendermos o discurso do poder empregado pelas elites, analisaremos o trajeto pelo qual um indivíduo necessitaria percorrer da porta de acesso da cidadela até o palácio do soberano micênico e quais edifícios estariam sendo protegidos e privilegiados nesse caminho. Além disso, realizaremos um breve estudo comparativo entre a simbologia contida na porta dos leões e materiais iconográficos provenientes de contexto funerário. A partir da análise espacial e iconográfica poderemos concluir que as muralhas ciclópicas e a porta dos leões em Micenas atuam como fronteiras de poder monumentalizadas, capazes de produzir comportamentos em moradores e visitantes, regular fluxos e legitimar o poder da elite, por meio de símbolos e edifícios ligados à religião e aos antepassados.

Palavras-chave: Fronteiras; Micenas; Monumentalidade; Muralhas ciclópicas; Porta dos leões.

\section{Introdução}

— ste artigo busca investigar os mecanismos pelos quais o poder das elites micênicas se materializava no espaço, por meio da criação de muralhas de caráter monumental nos sítios de Micenas, Midea

\footnotetext{
*Mestrando do programa de Arqueologia pelo Museu de Arqueologia e Etnologia da Universidade de São Paulo (MAE-USP) sob a orientação da professora doutora Maria Cristina Kormikiari Passos; membro do Laboratório de Estudos sobre a Cidade Antiga (Labeca). Apoio e financiamento do CNPq. 〈gustavojppeixoto@gmail.com〉.
}

e Tirinto entre os séculos XIV a.C. e XIII a.C. ${ }^{1}$. Para abordarmos a relação entre poder e materialidade, recorreremos à análise espacial de edifícios localizados entre a porta

1 texto foi motivado por discussões sobre as fronteiras e contato cultural no mundo antigo durante a disciplina de pós-graduação "Introdução às abordagens contemporânea em História e Arqueologia do Mediterrâneo antigo: mobilidade, insularidade, contato cultural e globalização" ministrada por Lilian de Ângelo Laky na Faculdade de Filosofia, Letras e Ciências Humanas da USP (FFLCH-USP) em 2019 e pelas discussões do Grupo de Pesquisa "Portos e Portas" do Labeca publicado em Aldrovandi, Hirata \& Kormikiari, 2011. 
principal da cidadela e o palácio do wanax ${ }^{2}$, e à análise iconográfica, para compreendermos a simbologia da "porta dos leões", principal via de acesso à cidadela.

Como ponto de partida abordaremos o debate acerca do conceito de fronteira e de limite, fundamentais para compreendermos o papel das muralhas e das portas de acesso. Neste trecho abordaremos o papel das portas, responsáveis pela mediação dos fluxos de pessoas e de produtos entre a cidadela e o assentamento extramuros.

Em seguida, empregaremos esses conceitos no caso específico de Micenas. Analisaremos a planta da cidadela, identificando as principais rotas de acesso e de fuga e quais áreas foram propositadamente englobadas no interior das muralhas por razões estratégicas e simbólicas. Nesta parte evidenciaremos as construções protegidas pelas muralhas e analisaremos o modo pelo qual essas construções estão dispostas no trajeto que vai da porta de acesso até o palácio, o centro administrativo da cidadela, localizado no ponto mais alto do sítio.

É importante notar que a via principal de acesso para o sítio é a monumental porta dos leões, que além de ser um marco responsável por delimitar e mediar o intercâmbio entre a cidadela e a área extramuros, possui a representação de dois leões ao redor de um pilar. Além da iconografia da porta de acesso possuir uma função apotropaica, ela se relaciona simbolicamente com os emblemas de poder utilizados pela aristocracia micênica, algo que é observado por meio da análise de selos reais e representações encontradas em objetos de contexto funerário ${ }^{3}$.

Por fim, faremos um balanço com conclusões preliminares acerca das fronteiras e portas no sítio de Micenas tentando encontrar respostas para os seguintes problemas:

1. Quais eram as principais vias de acesso às muralhas?

2 Wanax: palavra que designava o rei, responsável pelo comando do palácio (Cline 2010: 150).
2. Para qual direção as portas estão voltadas e por quê?

3. Como as muralhas ciclópicas eram percebidas pelos visitantes que se direcionavam ao palácio micênico?

4. De que modo a porta dos leões atua como fronteira simbólica?

5. Como os valores das elites se expressam na paisagem construída pelas muralhas?

Ao respondermos a esses questionamentos, teremos uma melhor compreensão sobre os mecanismos de expressão do poder em Micenas, evidenciando a importância estratégica de determinados edifícios para a própria manutenção simbólica e material desse poder.

\section{Métodos: discussão sobre o conceito de fronteira}

Influenciados pelos impactos da globalização no mundo contemporâneo, os estudos sobre as fronteiras têm ganhado grande atenção desde a década de 1990 (Guarinello 2010: 116). A globalização e a formação dos blocos econômicos fizeram com que os acadêmicos mudassem sua percepção sobre o papel das fronteiras nas relações entre Estados. Antes vistas como obstáculos, marcos divisórios e zonas de disputa entre os Estados nacionais, passaram a ser vistas e avaliadas como locais de negociação de produtos e de identidades, de trânsito de ideias, pessoas e serviços (Guarinello 2010: 121).

Essa percepção de que a fronteira é um local de disputa, um ambiente fluido, em constante mutação e negociação, teve impacto direto nos estudos sobre a identidade e a comunidade. Nascida no interior das Ciências Sociais, essa nova percepção sobre a fronteira encontra-se em diversos estudos sobre identidade social e coletiva, capital cultural, gênero, posicionamento de grupos étnicos, jurisdição de profissões, controvérsias científicas, direitos de determinados grupos, migração e contendas políticas (Lamont \& Molnár 2002: 167).

O impacto das pesquisas sobre a globalização fez com que o estudo sobre a fronteira se voltasse para seu papel de 
integração. Esses estudos, focados na compreensão das fronteiras entre identidades de grupos distintos, têm gerado conceitos e teorias como os de middle ground, creolização e hibridismo cultural (Lamont \& Molnár 2002: 187). Conceitos esses, que nos ajudam a compreender a fronteira como um espaço em constante construção e como um local de disputas materiais e simbólicas.

Nos trabalhos sobre a Antiguidade, a influência da globalização tem se refletido em campos de estudo, como, por exemplo, os contatos culturais no Mediterrâneo, a colonização grega, as identidades no Império Romano, as redes comerciais mediterrânicas e a diplomacia na Idade do Bronze (Guarinello 2010: 117). Um exemplo dessa influência é a afirmação categórica de Gras na introdução de seu livro O Mediterrâneo Arcaico:

\section{O mar é um espaço que ao mesmo tempo} divide e une. Fronteira e traço de união, é um cimento líquido que veicula os homens, os produtos $e$ as ideias. Em falsa simetria com os grandes desertos, é um espaço vazio, mas central, para o qual convergem os olhares ou o pensamento: atrai os homens que tem sabido desde sempre - pelo menos desde o Neolitico - que o domínio da terra pela agricultura é apenas um dos dois objetivos a atingir. Dominar o mar depende de outras lógicas e técnicas (Gras 1995: 7).

De acordo com Gras, o Mediterrâneo se torna um grande espaço "globalizado" de interação cultural e comercial. Para o autor, o mar possui uma dupla função. Por um lado, ele é capaz de promover a integração entre diferentes culturas, e por outro, ele serve como uma fronteira que divide essas diferentes culturas.

Neste artigo, investigaremos essa dupla característica atribuída ao Mar Mediterrâneo enunciada por Gras, mas aplicada ao contexto das muralhas da cidadela de Micenas, uma vez que essas muralhas ora assumem um caráter de integração e passagem, ora aparecem como barreira intransponível, um limite físico e simbólico para inimigos e estrangeiros.

Para iniciarmos a análise das muralhas e portas de Micenas, é fundamental refletirmos previamente sobre os conceitos de fronteira e limite, a fim de compreendermos o modo pelo qual grupos aristocráticos criavam e manejavam o espaço, criando marcos simbólicos e físicos na paisagem.

Partiremos da reflexão de Guarinello sobre o termo fronteira:

Fronteira, com efeito, tem sua origem etimológica na palaura francesa front (derivada de cabeça) e que designava, no século XV, o espaço vazio entre dois exércitos antes da batalha. Um obstáculo, portanto, mas também um lugar de passagem, um campo de negociação, um espaço de ação, um definidor dos grupos em ação. $\mathrm{O}$ campo semântico associado à fronteira é imenso, o que permite uma tipologia e um refinamento do conceito para casos específicos: de barreira intransponivel a obstáculo, ponto de passagem, margem, franja. É no jogo de negociações ao longo dessas fronteiras que a ordem se reproduz e se altera (Guarinello 2010: 120).

O autor pontua que o campo semântico é imenso para o termo fronteira, podendo significar tanto uma zona intersticial, que serve de passagem, como um local onde a passagem pode ser bloqueada. Para o autor, as fronteiras contêm em si próprias esse aspecto ambíguo. Para Guarinello, essas fronteiras podem ser "de isolamento, de autossuficiência", ou de integração, "negociação, cooperação e conflito". Tais fronteiras seriam responsáveis por abrir "percursos, canais, corredores e trajetos" (Guarinello 2010: 121).

Ainda refletindo sobre o caráter das fronteiras é importante distinguirmos a fronteira do conceito de limite. Segundo a geógrafa Lia Osório Machado, especialista no estudo das fronteiras entre os Estados nacionais, a fronteira é pautada por sua capacidade de integração. Para a autora, essa integração ocorre em razão da constante manipulação de estruturas sociais, políticas e culturais, promovidas pelo contato existente entre Estados fronteiriços.

Por sua vez, o limite promove a diferenciação e a separação entre entidades políticas ao "delimitar espaços mutuamente excludentes e definir o perímetro máximo de controle soberano exercido por um Estado 
central" (Machado 2006: 59). Desse modo, o limite serviria de obstáculo entre entidades políticas soberanas (Machado 1998: 42). Ele representa o "perímetro" até onde o poder de um Estado soberano consegue atuar no espaço.

O limite pode ser expresso por uma linha abstrata ou pode ser materializado na forma de uma barreira física como, por exemplo, um muro. Podemos citar como exemplares de limites materializados entre Estados: o muro de Berlim, o muro de Trump, entre os EUA e o México, e o muro da Cisjordânia, entre Israel e os territórios palestinos (Machado 2006: 59). Cada um desses muros tem a função específica de segregar espaços, impedindo o trânsito de indivíduos, produtos e ideias entre diferentes Estados. A construção desses muros, cuja função é segregar, separar e isolar, atende às demandas do poder central que os produz, e é motivada por questões de natureza geopolítica, econômica e/ou religiosa.

Desse modo, quando analisamos Estados nacionais, os limites representam a área de ação máxima de uma entidade política, enquanto a fronteira, atua como um espaço fluído, de intercâmbio e trocas entre territórios de entidades políticas diferentes.

No capítulo "Estudo das fronteiras no Mundo Antigo: caso Grego", do livro Estudos sobre o Espaço na Antiguidade, de Aldrovandi, Hirata \& Kormikiari (2011), esse conceito de fronteira é discutido no contexto peculiar da pólis grega. Segundo os autores a

fronteira é compreendida como uma área limitrofe, uma área de vigília, não necessariamente de maneira ostensiva, mas área de vigília da movimentação de entrada e saída de pessoas e de bens, que abrange [...] da fronteira até o centro do território (Aldrovandi et al., 2011: 130).

No caso da pólis ${ }^{4}$ grega, essas fronteiras se expressam arqueologicamente por meio de construções como templos, imagens de divindades, paliçadas, fortes e fortalezas. Essas

4 Para o uso das terminologias relacionadas ao espaço, derivadas da língua grega, usamos, neste artigo, a normatização de termos estabelecida pelo Labeca, disponível on-line em: 〈http://labeca.mae.usp.br/pt-br/glossary>. construções funcionam como marcos de território, cujo objetivo é defender e atacar. Nas pólis as muralhas (teikhe) marcavam as fronteiras sociais e simbólicas entre a aglomeração urbana (ásty) e a zona rural (khóra) (Aldrovandi et al., 2011: 131). Nesse sentido, as muralhas de uma cidade-estado ultrapassariam o estrito plano militar de defesa, assumindo implicações sociais e simbólicas (Aldrovandi et al., 2011: 166).

Por sua vez, para analisarmos as muralhas da Idade do Bronze na Grécia, não dispomos do mesmo tipo de fontes disponíveis nos períodos Clássico e Helenístico. As fontes escritas em Linear B na Idade do Bronze, relacionam-se de modo geral com registros administrativos dos palácios e não fornecem informações precisas sobre a construção das muralhas e seu relacionamento com aspectos simbólicos. Por essa razão, necessitamos acessar a documentação material e iconográfica para compreendermos as dimensões simbólicas criadas pelas muralhas.

Podemos obter informações sobre o modo como o poder materializa-se no espaço, por meio do estudo da disposição espacial de edifícios dentro e fora das muralhas dos sítios arqueológicos. A partir dessa análise, poderemos identificar quais edifícios são estratégicos para a manutenção do poder micênico. Entendemos como edifícios estratégicos aqueles que estão localizados na parte interior da cidadela, na área intramuros, a área protegida contra eventuais ataques inimigos. Enquanto a área extramuros, consideramos como zona agrícola e pastoril, que embora possua centros produtores e até mesmo moradias da elite, por motivos estratégicos, não foi englobada pela muralha da cidadela.

Adotamos o termo "muralhas" em razão do caráter monumental dos muros que formam as cidadelas micênicas. Esse aspecto fica evidente em Micenas: além dos blocos de alvenaria ciclópica formarem as muralhas, elas possuem também passagens internas, depósitos acoplados, baluartes, forjas, cisternas para captação de água, áreas de observação e torres (Simpson \& Hagel 2006: 34).

As muralhas da cidadela podem ser encaradas como fronteiras entre duas áreas distintas (intramuros e extramuros). Essas fronteiras podem 
atuar simbolicamente para criar distinções entre essas áreas, ou materialmente como barreiras planejadas para serem intransponíveis em tempo de guerra, a fim de proteger edifícios administrativos, comerciais, religiosos e assegurar a proteção da produção agrícola e da população em seu interior (Simpson \& Hagel 2006: 23).

Por sua vez, as portas assumem um caráter de fronteira na medida em que conectam áreas diferentes de um mesmo sítio, regulamentando e controlando a passagem entre essas áreas. Como trata-se de uma fronteira produzida por uma mesma entidade política, cabe-nos investigar o modo como a negociação entre esses espaços era feita, visando identificar o que está sendo dividido e separado, para visualizarmos se há também a produção de uma fronteira social e religiosa.

Para acessarmos a dimensão de fronteira simbólica produzida pela relação entre as muralhas e os edifícios intramuros, realizaremos uma análise iconográfica e espacial dos edifícios. Dessa forma, poderemos identificar o trajeto pelo qual um viajante, ou um habitante da área extramuros, teria que passar para chegar até o palácio. Esse trajeto consiste ele próprio em uma materialização do discurso simbólico do poder e, assim, poderemos identificar certos valores propagados pela entidade política.

Esse aspecto simbólico da muralha se expressa principalmente em seu próprio caráter monumental. As muralhas do sítio de Micenas são denominadas de ciclópicas, tanto pela sua técnica de construção, como por seu caráter monumental. Além de agirem como limites, que separam duas áreas diferentes de uma zona administrada por uma mesma entidade política, as muralhas atuam como fronteiras simbólicas, pois são construídas para impressionar a população com o poder do soberano micênico, servindo como um símbolo de status da elite e uma fronteira simbólica entre a cidadela murada e a área externa ${ }^{5}$.

5 Rapoport (1969: 3) discute a relação entre construções monumentais e poder: "Podemos dizer que os monumentos da grande tradição do design são construídos para impressionar tanto a população com o poder do patrono, como o grupo de designers e conhecedores com a esperteza do arquiteto e o bom gosto do patrono da obra” (tradução nossa).
Neste sentido, a muralha também possui o caráter de fronteira simbólica, uma vez que promove distinções entre espaços que possuem status diferentes dentro de um mesmo sítio e garantem a posse e o monopólio de recursos para a elite que se encontra dentro das muralhas (Lamont \& Molnár 2002: 168). Essas fronteiras serão analisadas na ótica do espaço construído, com o objetivo de identificar "na forma de disposição de estruturas arquitetônicas na paisagem a manifestação visual da ideologia que dá suporte a relações sociais assimétricas, típicas de sociedades rigidamente hierarquizadas" (Hirata \& Florenzano 2009: 121).

No caso da cidadela de Micenas, o maior elemento marcador dessa fronteira simbólica encontra-se na grande via de acesso ao interior das muralhas e passagem obrigatória para o palácio do rei, a chamada porta dos leões, que possui em seu topo, a representação de dois leões ao redor de um pilar. Esta via de acesso e os caminhos que vão da parte extramuros até o interior do palácio constituem também fronteiras simbólicas, na medida em que elas próprias produzem e influenciam comportamentos nas pessoas que transitam por aquele local (Rapoport 1969: 16). Essa porta monumental e sua relação com os caminhos de acesso ao palácio serão alvo da parte final deste artigo.

$\mathrm{Na}$ primeira parte notamos a influência das teorias sobre a globalização na criação e ressignificação do conceito de fronteira, e também como este conceito possui uma carga ambivalente que comporta a noção de obstáculo e zona intersticial de negociação. Além disso, destacamos que o conceito de fronteira geralmente é utilizado para analisar zonas limítrofes do território onde ocorre o contato entre grupos diferentes, geralmente nas margens dos Estados nacionais. Ainda abordamos o conceito de limite, que expressa uma zona que delimita, segrega e separa entidades políticas diferentes.

No caso das cidadelas micênicas, as muralhas expressam também o caráter ambivalente da fronteira. Ao mesmo tempo as muralhas têm a função de limite entre 
duas áreas de um território dominado por uma entidade política, e, ao mesmo tempo, constituem fronteiras sociais, simbólicas e até mesmo religiosas entre as zonas intramuros e extramuros. Com o intuito de realizar a mediação entre essas duas zonas, as portas regulam os fluxos e controlam a circulação entre essas áreas, consistindo assim em fronteiras negociáveis.

Por fim, discutimos que, além de seu objetivo mais evidente de defesa, as muralhas monumentais são fruto do espaço construído que produz comportamentos, condiciona caminhos, emite discursos ligados ao poder e produz formas de distinções sociais, tornando-se assim uma fronteira simbólica.

\section{Muralhas de Micenas: portas e delimitação do espaço}

A localização de Micenas na região da Argólida é estratégica. O sítio encontra-se entre as rotas terrestres do istmo de Corinto e a rota que vai para as montanhas da Arcádia, além de estar a uma distância de 15,56 quilômetros do mar Egeu ${ }^{6}$. A cidadela foi erguida no topo de uma colina calcária a 280 metros acima do nível do mar, em uma série de terraços concêntricos, em cuja parte mais elevada concentravam-se diversas residências (Conant \& Thomas 1999: 3). A muralha, por sua vez, contorna a colina e possui como via de acesso para área intramuros a porta dos leões que, segundo Simpson \& Hagel, está protegida por um bastião e uma antessala (2006: 34). O palácio está 38 metros acima da porta dos leões e fornece uma visão clara da planície abaixo.

6 Tomando como pressuposto que a velocidade média de caminhada é $4 \mathrm{~km} / \mathrm{h}$, um habitante de Micenas chegaria em cerca de 3 horas e 50 minutos ao litoral.
De acordo com a datação relativa proporcionada pelos estilos cerâmicos, as primeiras fortificações de Micenas teriam sido criadas entre 1420-1380 a.C. Enquanto as muralhas ciclópicas massivas teriam sido erguidas por volta de 1310-1200 a.C.

(Simpson \& Hagel 2006: 34). É neste último período que as muralhas passam a englobar diversos edifícios. Essas muralhas possuem cerca de 8 metros de altura com espessura variando entre 5 e 6 metros, e cobrem uma área de aproximadamente 30 mil metros quadrados, contando as próprias fortificações (Iakovidis 1983: 23).

As primeiras questões levantadas pelo artigo se referem às vias de acesso para o interior das muralhas e o direcionamento das portas. As muralhas contêm duas portas de acesso e duas passagens seguras na extensão nordeste do sítio (FIGURA 1). A porta dos leões, obra monumental, localizado na porção noroeste do sítio é sucedido por uma antessala e um bastião para guarnecer a entrada. Na porção norte há outra porta ou poterna, porta secundária, menor que a porta dos leões, e que possui um "triângulo de descarga" em sua parte superior.

Por sua vez, na extensão nordeste, existem duas entradas seguras (sally ports) para a fortificação (FIGURA 1), uma das quais foi obstruída durante o período helenístico (Loader 1996: 195). Nessa extensão leste também se localiza uma cisterna subterrânea, que é abastecida pela fonte de água Perseia próxima à cidadela. Essa cisterna era fundamental para a obtenção de água na área da cidadela em períodos de sítio prolongado ou de estiagem (Simpson \& Hagel 2006: 34).
7 De acordo com Robertson (1997: 34), o triângulo de descarga é uma técnica arquitetônica utilizada para evitar o colapso da estrutura de pedras sobre uma determinada porta. Essa técnica construtiva encontra-se presente também na porta de acesso do Tesouro de Atreu em Micenas. 


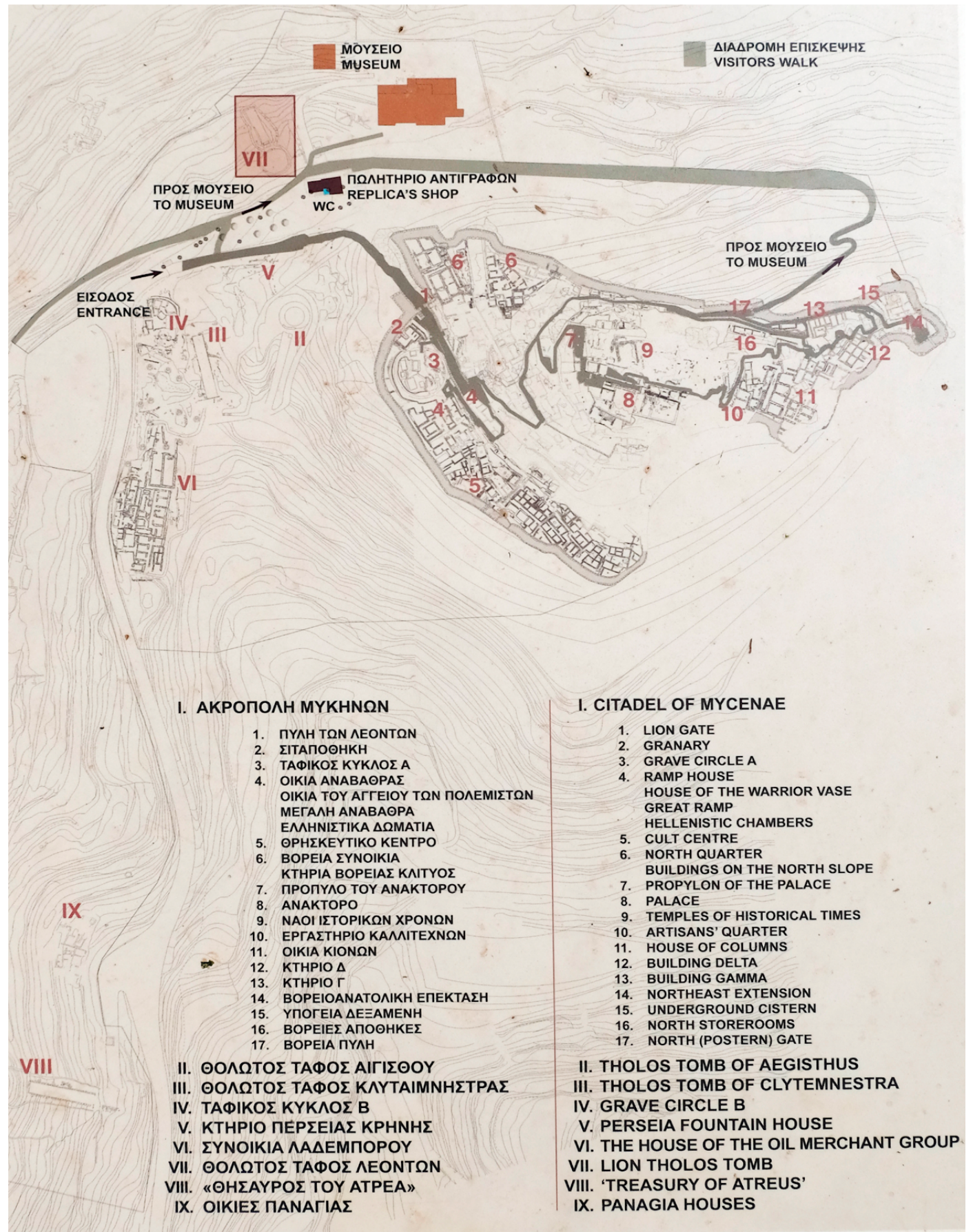

Fig. 1. Mapa de Micenas.

Fonte: Wikimedia Commons ${ }^{8}$. 
A entrada principal do sítio se conectava com quatro estradas. Essas estradas serviam para a comunicação, a vinda de insumos agrícolas e a própria defesa do sítio, uma vez que ao longo das estradas eram construídos fortes e entrepostos (Jansen 1994: 38). O capitão B. Steffen foi o primeiro a estudar a essas quatro estradas entre 1881 e 1882. Das quatro estradas localizadas, três delas se direcionam para o norte (FIGURA 2), ligando a Argólida ao sul da Coríntia, passando por Zygouriese e Nemea, enquanto a quarta estrada seguia para o sul, para as regiões de Prosymna, Argos, Midea e o litoral (Jansen 1994: 41).

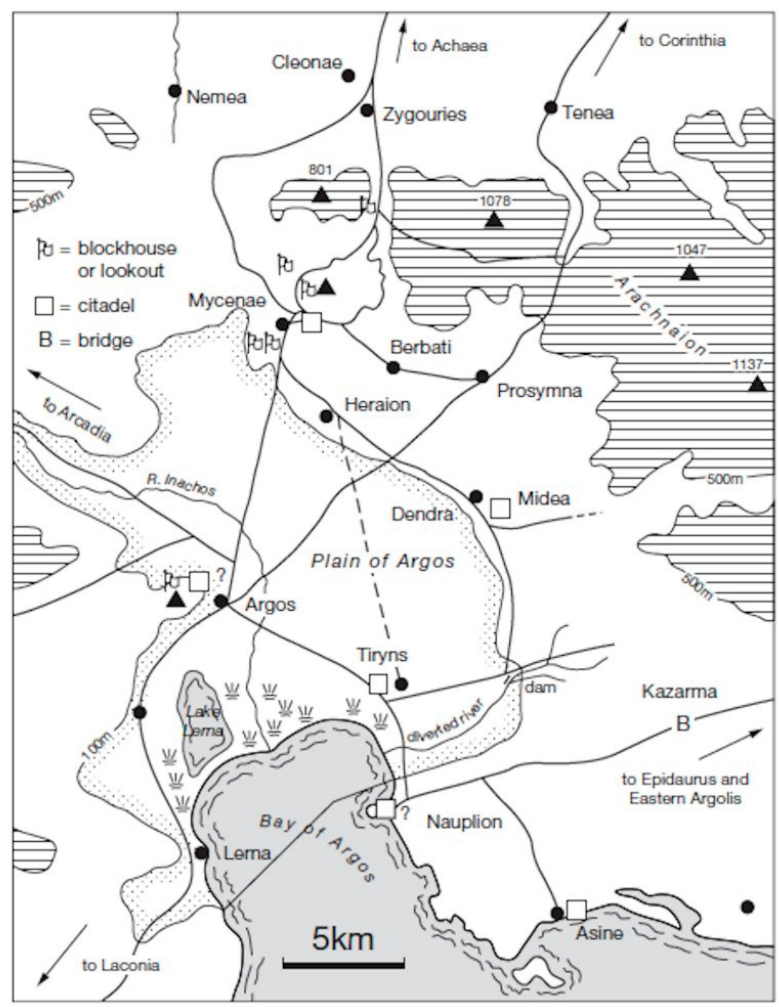

Fig. 2. Mapa da Argólida com as cidadelas (quadrados), assentamentos (pontos pretos), torres e entrepostos (bandeiras) e estradas (linhas pretas).

Fonte: Castleden (2005: 36).

Como mencionado anteriormente, as quatro estradas saíam da porta dos leões em razão das condições geográficas, montanhas ao norte (Profeta Elias) e ao sul (Monte Sara) e a ravina (Chavos) ao sul antes da entrada do sítio, o que direcionava os fluxos de bens e pessoas de leste e oeste para a porta central localizada na porção noroeste do sítio. Por outro lado, a porta norte, dava acesso apenas a uma estrada na direção leste e se conectava às outras estradas que saíam da porta dos leões (Jansen 1994: 42).

Desse modo, podemos afirmar que em Micenas a principal via de acesso, que fazia conexão com a parte externa e com as quatros estradas no entorno do sítio partia diretamente da porta dos leões. Ao passo que, a porta norte serviria como uma porta secundária, uma saída possivelmente utilizada como rota de fuga em tempos de guerra, uma vez que apenas uma das estradas que saía da porta dos leões se conectava à porta norte. $\mathrm{O}$ controle do fluxo de produtos $\mathrm{e}$ pessoas nitidamente era exercido pela porta dos leões, que servia como uma fronteira material e simbólica do poder micênico.

Como comentado anteriormente, a porta dos leões localizava-se à oeste do sítio em um 
ponto de afunilamento com a intenção de proteger a entrada para a cidadela. Por exemplo, um exército que desembarcasse no litoral da Argólida necessariamente teria de passar pela ravina e ir contornando as muralhas em nítida desvantagem de defesa contra flechas até acessar a porta central que está guardado pelo bastião. O mesmo processo ocorria se o exército viesse do norte da Argólida, neste caso, embora o trecho das muralhas a ser contornado fosse menor, a elevação no noroeste do sítio colocava o inimigo em nítida desvantagem. Ou seja, a topografia era fundamental para a defesa do sítio e determinava o traçado das muralhas.

Traçado esse que tinha como objetivo proteger os principais edifícios micênicos e oferecer abrigo à população e aos animais durante períodos de sítio durante tempos de guerra9. Ao observarmos a planta do sítio notaremos que logo após a porta dos leões, encontra-se um celeiro, posicionado neste local por ser o mais próximo possível das zonas de produção e para garantir a proteção dos insumos administrados pelo palácio. É interessante notar que na porta norte não se encontra um celeiro em suas proximidades, mas uma sala de armazenamento. Isto reforça o papel de fronteira material da porta dos leões com a zona agrícola $\mathrm{e}$ levanta questões acerca do que era armazenado e produzido próximo da porta norte.

Após o celeiro, no interior das muralhas há o "Círculo Tumular A". Descoberto em 1876 por H. Schliemann, o Círculo Tumular A consiste em um conjunto de 6 túmulos retangulares cavados na pedra e na terra com uma borda na parte inferior para sustentar o teto. Além disso, essa construção é englobada por duas fileiras de placas retangulares de pedra calcária (FIGURA 3). Nos túmulos no interior do Círculo Tumular A foram encontrados 19 esqueletos, sendo nove mulheres, oito homens e duas crianças. Junto com os homens foram encontradas armas como espadas, adagas, lanças e facas. Alguns deles usavam também máscaras de ouro. Eles são retratados como heróis e caçadores em anéis encontrados nas sepulturas. Além disso, foram encontradas diversas joias, como, por exemplo, discos de ouro nas roupas dos homens e das mulheres e copos de ouro e prata (Cline 2010: 284).

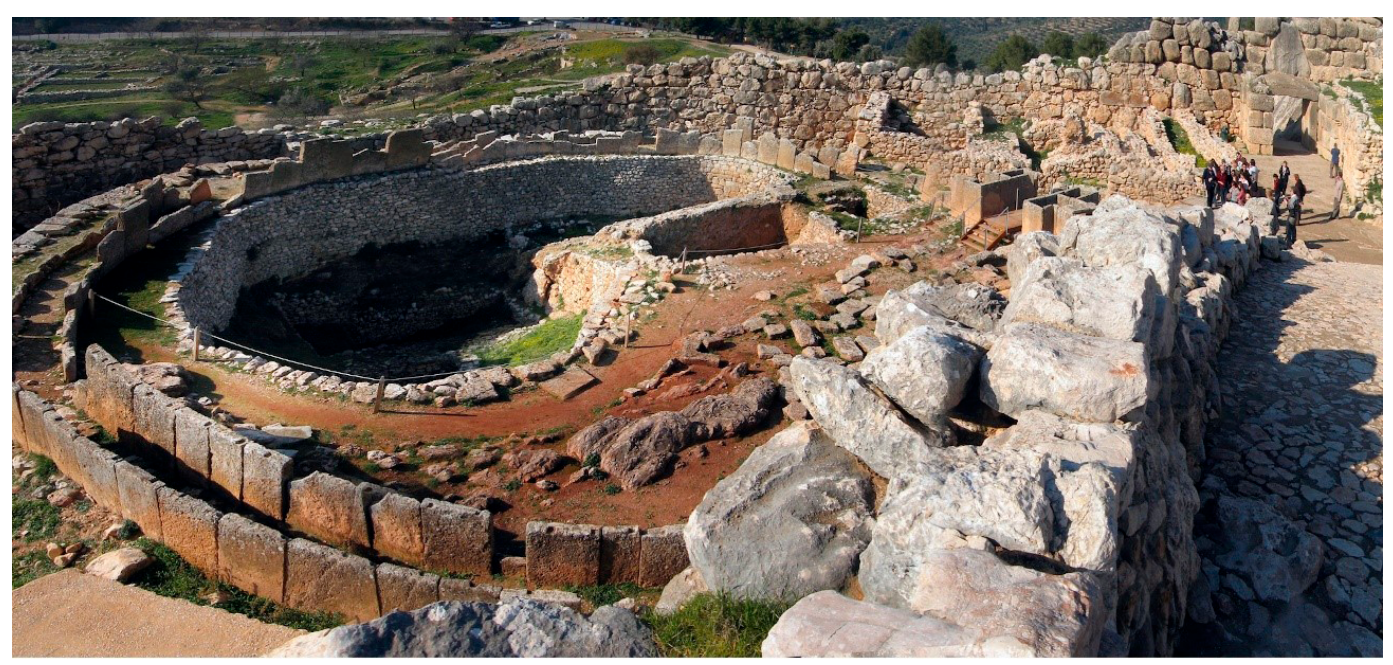

Fig. 3. Círculo Tumular A (esquerda) e Porta dos leões (direita).

Fonte: Wikimedia Common ${ }^{10}$.

9 Conforme observado por Simpson \& Hagel (2006: 23) dentro das muralhas existiam espaços vazios que provavelmente tinham a função de alojar a população em caso de ataques externos. Esses espaços vazios são observados em diversas cidadelas micênicas. Em Gla na Beócia notamos grandes extensões de espaços vazios, enquanto em Micenas notamos apenas alguns espaços sem construções.

10 Disponível em: <https://bit.ly/3114dNu>. Acesso em: 27/02/2020. 
Embora o Círculo Tumular A tenha sido utilizado incialmente entre 1600-1500 a.C. ele passou por um restauro, teve seus muros substituídos e foi englobado pelas muralhas entre 1310-1200 a.C. Isto indica que existia um respeito e uma reverência aos mortos sugerindo um culto aos fundadores da dinastia real, servindo também como fonte legitimadora do poder dos reis micênicos (Cline 2010: 284).

Após o Círculo Tumular A, encontramse uma série de rampas que levam ao palácio do soberano micênico, diversos edifícios, como a casa do vaso dos guerreiros, a casa sul e um centro de culto. De acordo com Lupack, este seria o centro de culto micênico mais impressionante, conectado pela via processional, tinha cinco construções centrais: o mégaron, o templo, o quarto com um complexo de afrescos, o santuário gama e a casa de Tsountas (Cline 2010: 265). Nestes edifícios foram encontrados diversos tipos de altares, estatuetas, locais para libações, poços para oferendas e chifres de consagração.

É importante notarmos como diferentes edifícios de culto e inclusive uma via de procissões encontram-se englobados pelas muralhas, novamente servindo como fonte de legitimação aos poderes dos reis micênicos e como forma de criar uma fronteira de proteção sobrenatural às pessoas que ingressassem na cidadela. Para um indivíduo se deslocar da porta dos leões até o palácio do wanax, ele necessariamente tinha de passar diante dos túmulos de antepassados míticos, andar ao lado de templos e percorrer vias processionais.

Ainda no interior das muralhas temos o núcleo administrativo de Micenas, o palácio com seus arquivos reais e outros ambientes de culto. Além disso, temos um segundo arquivo de tabletes de Linear B na extensão leste, o quarteirão dos artesãos na parte leste abaixo do palácio e a já mencionada cisterna construída junto à porção norte das muralhas a fim de garantir o suprimento de água diante de cercos.

Desse modo, notamos que o centro administrativo utiliza as muralhas para proteger e monopolizar bens materiais estratégicos como água, alimento, o núcleo de produção cerâmica e os arquivos administrativos. As muralhas tinham a finalidade de proteger o capital simbólico caro à aristocracia, como a preservação de túmulos dos ancestrais (Círculo Tumular A), de edifícios cerimonias (centro de culto) e de rotas de procissão. Além disso, as muralhas serviam de fronteira entre as zonas agrícolas e pastoris na área extramuros e as zonas de acumulação e monopolização de bens, que são reforçados e legitimados por marcadores simbólicos ligados aos ancestrais e à religião.

\section{Muralhas ciclópicas monumentais}

Resta-nos agora compreender qual era a impressão causada nas pessoas que viviam próximas às muralhas e nos viajantes, compreendendo como o aspecto monumental delas servia de fronteira simbólica e produzia comportamentos. Primeiro abordaremos a percepção que os gregos após a Idade do Bronze tinham sobre essa cidadela, quais aspectos da construção definem a tipologia arqueológica de alvenaria ciclópicas, qual é a definição de monumentalidade adotada e como esse aspecto influenciava na percepção de moradores e visitantes.

Os impactos dessa monumentalidade no plano das ideias estão documentados na percepção que os gregos posteriores à Idade do Bronze tinham sobre Micenas. Os epitetos homéricos de "bem construída", "dourada" e "cidade dos caminhos que se espalham" (Fletcher 1941: 6) revelam o modo como os gregos percebiam a grandeza de Micenas, associando-a com sua própria construção monumental, sua riqueza e sua ampla rede de estradas. Além disso, a tradição mítica atribuía a construção das muralhas aos ciclopes. Os ciclopes são seres mitológicos, filhos de Poseidon com as musas, que possuíam apenas um olho na fronte e eram detentores de grande força física.

Na lenda da construção das muralhas de Micenas, o rei Proitos de Tirinto entrara em guerra com o irmão Akrisios, rei de Micenas e avô de Perseu. Proitos, então trouxe os ciclopes da Anatólia para construir as muralhas de Tirinto (Conant \& Thomas 1999: 5). Curiosamente na Anatólia, local de origem 
desses ciclopes construtores no mito, existiam diversos palácios fortificados, que utilizavam blocos massivos na construção das muralhas, como, por exemplo: Troia VI e Hattusas (atual Bogazköy e antiga capital do Império Hitita). Em torno de uma geração após a história de Proitos, Perseu, rei de Micenas, teria empregado os ciclopes para a construção de muralhas no referido sítio (Pausanias 1918: 331) ${ }^{11}$.

Motivados inicialmente pela tradição mítica, arqueólogos e historiadores começaram a denominar essas muralhas como obras da alvenaria ciclópica. Segundo Simpson e Hagel, as muralhas ciclópicas possuiriam as seguintes características: o uso de blocos grandes e massivos, pedra calcária como matéria-prima e formação de blocos com espessura específica para evitar o colapso da estrutura.

Para formar esses blocos era utilizada a técnica da serra de pêndulo de bronze para cortar o calcário e produzir blocos quadrados, utilizados principalmente nas vias de acesso e em torres. Contudo, a maior parte das muralhas de Micenas foi feita com base na alvenaria ciclópica sem corte retangular, no qual grandes blocos de pedra foram ligados com o uso de pedras menores combinadas com terra e argila (FIGURA 4) (Simpson \& Hagel 2006: 23).

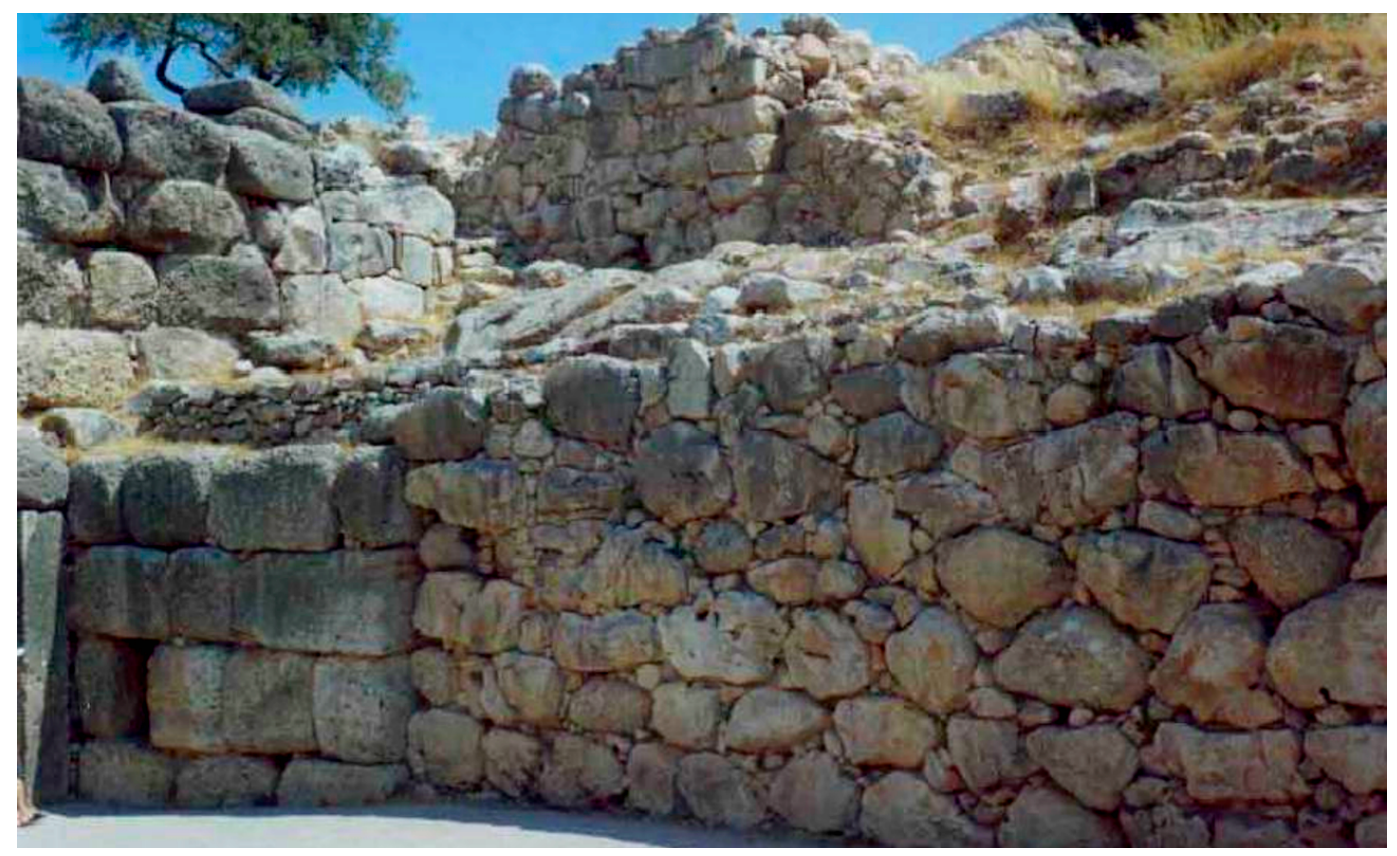

Fig. 4. Alvenaria ciclópica com corte retangular (esquerda) e blocos sem corte retangular com pedras menores conectando os interstícios entre blocos (direita).

Fonte: Wikimedia Commons ${ }^{12}$.

Assim, o caráter externo geral das muralhas ciclópicas é marcado pelo uso de

11 "Ainda permanecem, contudo, parte do muro da cidade, incluindo a porta dos leões. Esses também é dito que foram obras dos ciclopes, que fizeram para Proitos os muros de Tirinto" (Pausanias 1918: 331; tradução nossa).

12 Disponível em: 〈https://bit.ly/3gxnJTs $>$. Acesso em: 27/02/2020 grandes e frequentemente massivos blocos e de pedras menores usadas nos interstícios desses blocos maiores. Terra e argila completavam e conectavam esses blocos. Esses blocos intersticiais serviam como um calço para evitar que os blocos escorregassem em algum declive ou tremor, além disso, eram usados durante o processo de preenchimento dos vãos com argila, 
na medida em que os blocos intersticiais eram colocados para prevenir o colapso das juntas, importantes para resistir à terremotos (Simpson \& Hagel 2006: 24).

Em razão do enorme peso dos blocos, as fundações desse tipo de muralhas tinham de ser sobre o leito rochoso. Assim, o trajeto de parte das muralhas e suas variações de altura e direção eram influenciados pelas características e fissuras desse leito, impedindo que a construção tivesse um caráter regular. Nas fundações e partes mais baixas das muralhas a argila era utilizada como uma espécie de cimento complementado por solo úmido e pedras a fim de criar uma camada com alta aderência e evitar o colapso da estrutura (Simpson \& Hagel 2006: 25).

É importante ressaltar que o topo das muralhas, principalmente em grandes sítios como em Micenas e Tirinto, era transitável e inclusive facilitava a comunicação dentro do sítio. Por exemplo, era muito mais rápido ir da cisterna leste até a porta dos leões por cima das muralhas do que por dentro do sítio, que possuía muitas ruas e construções (Simpson \& Hagel 2006: 25). Além desses aspectos, sobre os portões eram utilizados triângulos de descarga, que além de uma funcionalidade prática, provavelmente tinham um caráter simbólico expressando o discurso estético das aristocracias micênicas.

De acordo com Trigger, um edifício expressa monumentalidade na medida em que excede em "escala” e em sua "qualidade de construção" suas necessidades de funcionamento. Assim, a monumentalidade liga-se ao "consumo conspícuo" (Trigger 1990: 122). Segundo Hirata:

O controle de energia constitui " a mais fundamental e universalmente reconhecida medida de controle de poder" [...] A arquitetura monumental é uma forma de alta visibilidade e durabilidade a comunicar esse tipo específico de consumo "extraordinário" associando-o a um governante ou a uma camada hegemônica detentora de poder [...] O princípio do consumo conspícuo seria, pois, a contrapartida oposta de outro comportamento muito observado nas sociedades humanas, o princípio do "menor esforço", ou seja, o recurso a um gasto maior de energia no tempo curto para reduzir o dispêndio de energia no tempo longo (Hirata 2009: 122).

Nesse sentido, a alvenaria ciclópica encontrada nas muralhas e nos tolos micênicos representam formas desse consumo conspícuo ao excederem suas necessidades funcionais e se tornarem símbolo de poder daqueles que monopolizam os recursos de uma sociedade. Mais que isso, as muralhas e os portões agem como fronteiras simbólicas ao demarcar a entrada para o espaço intramuros, que contém os edifícios administrativos, religiosos e estratégicos como os celeiros e centros de produção. Desse modo, as muralhas delimitam uma área que monopoliza e controla importantes recursos da região (Lamont $\&$ Molnár 2002: 168).

Por essa razão, essas fronteiras simbólicas expressam e reforçam fronteiras sociais, na medida em que manifestam o acesso desigual à distribuição de recursos materiais e não materiais. Enquanto a fronteira simbólica existe em um nível subjetivo, a social se manifesta fisicamente ao separar espacialmente indivíduos (Lamont \& Molnár 2002: 168-169).

Para um habitante da zona extramuros ou um viajante, as muralhas de 8 metros construídas sobre o monte calcário, por si sós, já expressariam a monumentalidade e simbolizariam o poder dos soberanos que as construíram. Como se não bastasse, o palácio se localiza na parte mais alta do sítio, 30 metros acima ${ }^{13}$ da porta principal, destacando-se na paisagem e visível para pessoas que se encontram distantes do sítio. Surgindo como uma barreira instransponível, cuja principal via de acesso está guardada por um bastião, com os símbolos da monarquia micênica, guardada pelos os antepassados (Círculo Tumular A) e os deuses (conjunto de edifícios de culto após os portões).

Por fim, trataremos dos aspectos simbólicos contidos na porta dos leões (FIGURA 5). Nesta porta principal do sítio notamos um triângulo

13 Medições realizadas com o auxílio do Google Earth. A porta principal encontra-se a 243 metros acima do nível do mar, enquanto a sala do trono encontrava-se a 272 metros acima do nível do mar. 
de descarga onde está entalhado a figura de dois leões que estão sobre duas plataformas e que se posicionam diante de um pilar decorado, que consiste na representação estilizada de uma divindade feminina. Segundo a reconstituição proposta por Blackwell (2014: 474), que analisou diversos selos micênicos e se atentou às técnicas utilizadas para a construção da decoração da porta principal, os leões teriam suas faces voltadas para fora da cena e não para o pilar (FIGURA 6).

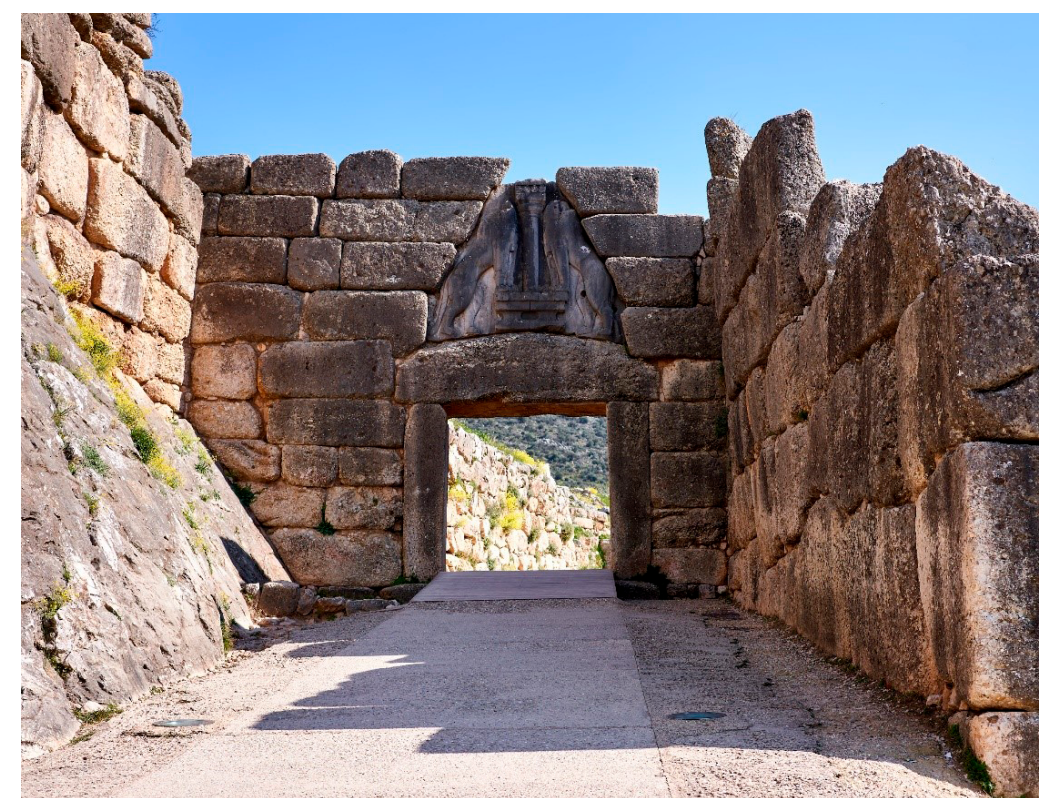

Fig. 5. Porta dos leões.

Fonte: Wikimedia Commmons ${ }^{14}$.

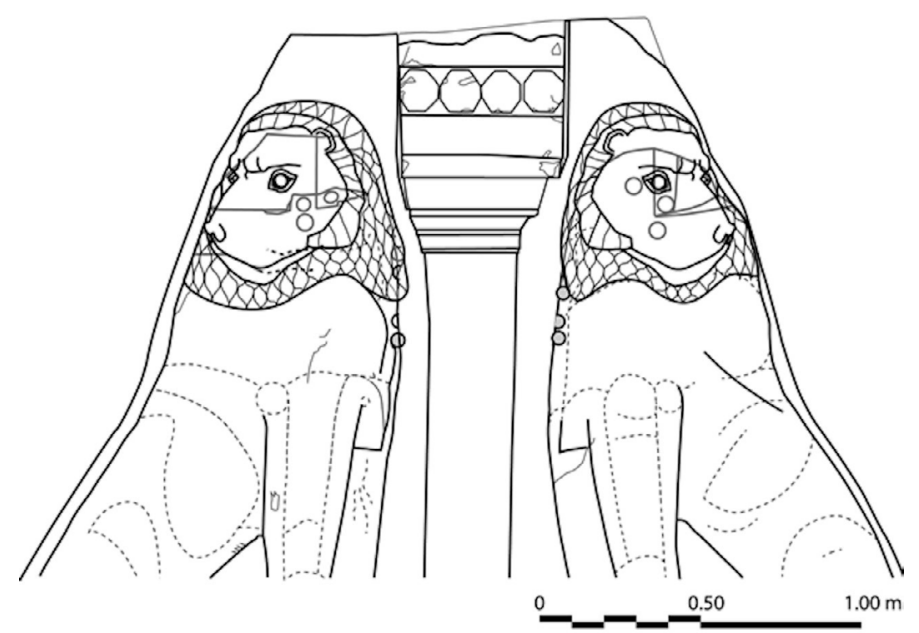

Fig. 6. Reconstituição do motivo presente na porta dos leões.

Fonte: Blackwell (2014: 476).

14 Disponível em: <https://bit.ly/2FWGmUm>. Acesso em: 27/02/2020. 
$\mathrm{O}$ argumento de que o pilar representaria uma divindade feminina provém da existência de objetos disponíveis no Museu Britânico (Kenna 1967: 158), como uma gema de ágata encontrada em Micenas. Nesta gema (FIGURA 7) uma divindade feminina aparece sentada sobre trono em forma de cabeça de leão, enquanto está cercada por um leão (direita) e uma leoa (esquerda) que olham para a parte externa da cena. A divindade feminina direciona seu corpo à direita no sentido do leão. Cena semelhante encontra-se em uma ágata fina também encontrada em Micenas que retrata uma divindade feminina agitando os braços e cercada por um leão e uma leoa, novamente a divindade olha em direção ao leão (FIGURA 8).

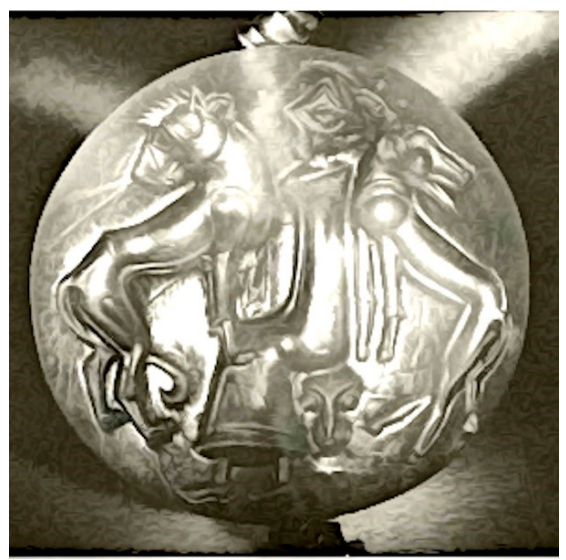

Fig. 7. Gema de ágata encontrada em Micenas. Deusa rodeada por leões e sentada sobre um trono em forma de cabeça de leão. Coleção do Museu Britânico.

Fonte: Kenna (1967: 158).

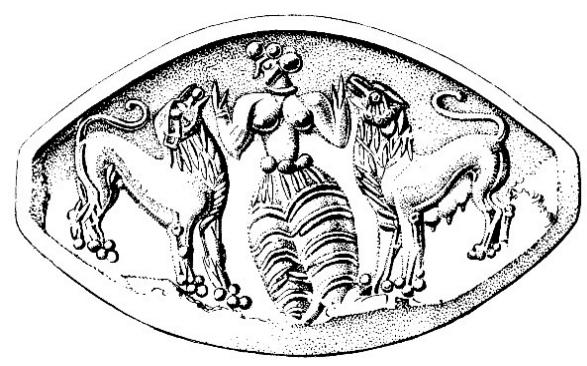

Fig. 8. Ágata Fina retratando uma deusa rodeada por um leão (esquerda) e uma leoa (direita). Coleção do Museu de Berlim.

Fonte: Evans (1901: 164).
De acordo com Blackwell (2014: 473) “apesar da natureza felina dos animais em razão das marcas de ferramentas, o sexo deles é mais difícil de ser determinado. A identificação dos animais se leões ou leoas tem continuado sem solução em razão da falta das cabeças e da juba”. Embora não haja um consenso, para o autor provavelmente seriam dois leões em razão dos vestígios das jubas e das marcas de sua musculatura. Contudo, as evidências iconográficas comentadas acima sugerem o contrário.

A representação de leões na sociedade micênica costuma fazer referência aos valores guerreiros e às elites micênicas. De acordo com Thomas, o centro de produção imagética que trata de temas relacionados a leões encontrase em Micenas. Nesse sítio há vinte e quatro objetos que fazem esse tipo de representação (Thomas 2004: 164). Isto indicaria que por várias gerações os nobres guerreiros foram enterrados com imagens de leões em suas tumbas, principalmente no período Heládico Tardio I (1600-1500) a.C..$^{15}$, o mesmo período de construção do Círculo Tumular A.

É interessante notar que esses achados arqueológicos com imagens de leões foram encontrados em tumbas com enterramentos de gêneros diferentes e de faixas etárias diferentes. De acordo com a autora, nos túmulos masculinos temos leões representados em adagas, enquanto que em enterramentos femininos e infantis, encontramos as cenas retratando leões interagindo de forma violenta com figuras humanas. Segundo a autora, as cenas que contém leões encontradas em Micenas possuem um caráter violento, diferentemente de representações de leões em outros sítios, como nas Cíclades e em Creta (Thomas 2004: 172). Diversos estudos associam o caráter de violência das cenas aos valores conectados ao gênero masculino como agressividade, amadurecimento e proeza (Thomas 2004: 184), contudo é interessante

15 Utilizamos a cronologia relativa baseada em tipos cerâmicos. O Heládico Tardio I (Late Heladic I) teria ocorrido entre 1600 a.C. e 1500 a.C. Para saber mais sobre a cronologia relativa na Grécia, ver Simpson \& Hagel (2006: 21). 
notarmos que grande parte das representações se encontram associadas a enterramentos femininos e infantis.

Esse tipo de cena presente na iconografia denota que a entrada da cidadela estava protegida por uma divindade e também pela aristocracia que a governava. Fornecendo assim uma fronteira simbólica entre o espaço sagrado, protegido pelos deuses e ancestrais, e o espaço profano. A porta afasta os inimigos materiais e sobrenaturais da cidadela sagrada, garante a proteção de recursos escassos e afirma os valores da aristocracia guerreira.

\section{Conclusão}

Ao longo do artigo buscamos traçar um breve panorama da análise espacial das muralhas e das portas em relação aos demais edifícios de Micenas com base nas discussões sobre fronteiras e limites. Notamos a posição estratégica da porta dos leões, que serve como fronteira material a fim de garantir proteção e regulamentar o intercâmbio entre o espaço interno e externo da cidadela. Além disso, percebemos a conexão direta entre a porta dos leões e as estradas que saem do sítio, seu papel de fronteira simbólica ao retratar valores religiosos e aristocráticos, que estão presentes na iconografia dos leões diante do altar. Altar que funciona como um símbolo de uma parte, que representa um todo socialmente compartilhado, no caso, uma divindade feminina. Deusa responsável por proteger religiosamente a cidadela, indicando que a própria cidadela estaria contida no interior de um perímetro sagrado. Argumento que é reforçado pela quantidade de edifícios de caráter sagrado dentro da cidadela, como o Círculo Tumular A, centros de culto e diversos espaços sagrados no interior do palácio.

Ao analisarmos a planta do sítio respondemos algumas questões enunciadas no início deste trabalho. Conseguimos por meio da análise espacial de Micenas identificar uma via de acesso principal na seção noroeste, a porta dos leões, uma porta secundária, a porta norte, e duas entradas seguras (sally ports) no setor nordeste do sítio. Notamos que a porta dos leões centraliza as rotas de acesso ao sítio por ser o ponto de chegada de quatro estradas, três que se conectam ao norte do Peloponeso e uma que vem da região litorânea no sul da Argólida. Percebemos que a porta norte, considerada como porta secundária ou rota de fuga, se conecta com estradas que se direcionam para o portão principal e para a região leste (oposta à porta principal), enquanto as duas entradas seguras (sally ports; poternas) consistem em rotas de entrada para pedestres e se localizam em locais de difícil acesso.

Exploramos também o caráter monumental do sítio e de suas muralhas ciclópicas. Identificamos os aspectos técnicos que garantem essa monumentalidade, as razões estratégicas e religiosas que motivaram a proteção de certos edifícios pelas muralhas, questões acerca da visibilidade do sítio, o entendimento das muralhas como afirmação do consumo conspícuo por parte das camadas sociais que monopolizam recursos, além da percepção de viajantes e inimigos diante das extensas e altas muralhas.

Em seguida, ao simularmos o trajeto de um viajante da entrada do sítio até o palácio do wanax, percebemos que o indivíduo necessitaria passar por várias construções que possuem uma carga simbólica atrelada à aristocracia micênica. Por exemplo, ele necessitaria passar por portões monumentais, que possuem a representação estilizada de uma deusa (pilar) e de leões (símbolos aristocráticos), indicando que a cidadela era protegida pelos deuses e por uma linhagem de guerreiros. Em seguida, ele passaria por um monumento funerário em honra aos antepassados, o Círculo Tumular A, com os despojos dos ancestrais míticos. $\mathrm{Na}$ sequência precisaria passar também por um conjunto de edifícios de culto e uma série de vias processionais até chegar na entrada do palácio do soberano. É importante lembrar que, caso o visitante desejasse conversar com o soberano micênico, ele ainda precisaria chegar até o mégaron (sala real). Para isso, ele teria de passar por diversas salas e antessalas do palácio até chegar nessa sala, que propositalmente se encontra em um dos pontos mais altos da acrópole. 
Desse modo, percebemos que as muralhas possuem um caráter prático de defesa, mas também uma dimensão simbólica. Dimensão que se expressa quando relacionamos essas muralhas com os tipos de edifícios englobados por elas e o tipo de trajeto que é produzido nessa relação. Esse trajeto gera sentidos, expõe valores e possui um discurso atrelado aos ancestrais e à religião, que é capaz de legitimar o poder da aristocracia e materializar fronteiras simbólicas e sociais no espaço.

Por fim, concluímos que as muralhas ciclópicas são fronteiras de poder monumentalizadas, que possuem a função estratégica da defesa e de exposição do poder central, doutrinando o espaço físico, regulando fluxos e produzindo comportamentos em moradores e visitantes. A análise espacial dessas muralhas em relação aos edifícios vizinhos é um campo fértil para estudos que buscam identificar as tecnologias do poder utilizadas pelas elites micênicas. Estudos que podem se concentrar na questão material de fixação de limites e fronteiras entre áreas diferentes de um território, ou que podem se debruçar sobre questões simbólicas capazes de revelar os alicerces que legitimam o poder da aristocracia micênica.

\section{Agradecimentos}

Agradeço à minha esposa Lilian Gobby Amstalden Peixoto e ao meu filho Daniel Amstalden Peixoto pelo constante apoio e inspiração, à minha orientadora Prof ${ }^{\mathrm{a}}$. Dr ${ }^{\mathrm{a}}$. Maria Cristina Nicolau Kormikiari Passos, pelo constante auxílio e ensinamentos, à Profa. Dra ${ }^{\text {a }}$ Elaine Farias Veloso Hirata e à Prof ${ }^{\mathrm{a}}$. Dr ${ }^{\mathrm{a}}$. Beatriz Borba Florenzano pelo acolhimento no Labeca, aos meus colegas do Labeca e do MAE. Agradeço ainda aos meus pais Gildo e Sandra e à minha avó Rachel Helena Violante Peloso.

Esse trabalho foi realizado graças ao apoio do Labeca (Laboratório de Estudos da Cidade Antiga), do MAE (Museu de Arqueologia e Etnologia) e do CNPq, que financiou o desenvolvimento dessa pesquisa.

PEIXOTO, G.J.P. Boundaries, doors and walls in the citadel of Mycenae. R. Museu Arq. Etn., 35: 135-151, 2020.

\begin{abstract}
This paper explores the concept of boundaries in the ancient world using the material and symbolic boundaries produced by the walls and doors of the citadel of Mycenae during the 14th and 13th centuries BC as a case study. This study aims to identify how Mycenaean elites materialized their discourse of power in space, be it in the construction of monumental cyclopean walls, in the creation of symbolic landmarks such as the "lion gate", or in the purposeful and strategic arrangement of buildings that lie between the main gate and the palace of the Mycenaean king. To understand the discourse of power employed by the Mycenaean elites, we analyze the trajectory taken by an individual who would need to walk from the access gate to the palace at the top of the citadel and which buildings would be protected and privileged on that path. Additionally, we conduct a brief comparative study between the semiology contained in the lion gate and iconographic materials found in a funerary context. Based on spatial and iconographic analysis, we conclude that the cyclopean walls and the "lion gate" in Mycenae act as monumentalized power frontiers, capable of producing behaviors among residents and visitors, regulating flows, and legitimizing the power of the elite through symbols and buildings connected to religion and ancestors.
\end{abstract}

Keywords: Boundaries; Cyclopean walls; Lion gate; Monumentality; Mycenae. 


\section{Referências bibliográficas}

Aldrovandi, C.E.V.; Hirata, E.F.V.; Kormikiari, M.C.N. (Orgs.) 2011. Estudos sobre o Espaço na Antiguidade. Edusp, São Paulo.

Blackwell, N. 2014. Making the Lion Gate relief at Mycenae: tool marks and foreign influence. American Journal of Archaeology 118: 451-488. Disponível em: <https://bit.ly/2ECVNR2>. Acesso em: 27/02/2020.

Castleden, R. 2005. The Mycenaeans. Routledge, New York.

Cline, E. 2010. The Oxford Handbook of The Bronze Age Aegean (ca. 3000-1000 BC). Oxford University Press, Oxford.

Conant, C.; Thomas, C. 1999. Citadel to City-State. Indiana University Press, Bloomington.

Evans, A.J. 1901. Mycenaean tree and pillar cult and its mediterranean relations. The Journal of Hellenic Studies 21: 99-204.

Fletcher, F. 1941. Tiryns, Argos, Mycenae in legend and literature. Greece \& Rome 11: 1-9. Disponível em: <https://bit.ly/3husHBQ $>$. Acesso em: 27/02/2020.

Gras, M. 1995. O Mediterrâneo arcaico. Teorema, Lisboa.

Guarinello, N. 2010. Ordem, integração e fronteiras no Império Romano: um ensaio. Mare Nostrum 1: 113-127. Disponível em: <https://bit. ly/3hsEO2l >. Acesso em: 27/02/2020.

Hirata, E.F.V.; Florenzano, M.B.B. 2009. Estudos sobre a cidade antiga. Edusp; Fapesp, São Paulo.

Iakovidis, S. 1983. Late Helladic citadels on mainland Greece. Brill, Leiden.

Jansen, A. 1994. Stations along the roads in the area of Mycenae. Tese de doutorado. Universidade da Pensilvânia, Filadélfia.

Kenna, V.E.G. 1967. London, British Museum. In: Kenna, V.E.G. Die Englischen Museen II. London, British Museum; Cambridge, Fitzwilliam Museum; Manchester, University Museum; Liverpool, City
Museum; Birmingham, City Museum. Gebrüder Mann, Berlin, 135-172.

Lamont, M.; Molnár, V. 2002. The study of boundaries across the social sciences. Annual Review of Sociology 28: 167-195. Disponível em: <https://bit. ly/3ljWaR6>. Acesso em: 27/02/2020.

Loader, N. 1996. A possible east Sally-Port in the northeast extension at Mycenae? A Brief Note. The Annual of the British School at Athens 91: 191-196. Disponível em: <https://bit.ly/2FQaosI>. Acesso em: 27/02/2020.

Machado, L. 1998. Limites, fronteiras e redes. In: Strohaecker, T., et al. (Orgs.). Fronteiras e espaço global. AGB, Porto Alegre, 41-49.

Machado, L. 2006. Cidades na fronteira internacional: conceitos e tipologia. In: Anais da 2 Conferência internacional de desenvolvimento urbano em cidades de fronteira do Instituto de Arquitetos do Brasil, 2006, Foz do Iguaçu, 58-69.

Pausanias. 1918. Description of Greece. Tradução W.H.S. Jones, H.A. Ormerod. William Heinemann, London.

Rapoport, A. 1969. House form and Culture. PrenticeHall, Upper Saddle River.

Robertson, A. 1997. Arquitetura grega e romana. Martins Fontes, São Paulo.

Simpson, R.H.; Hagel, D. 2006. Mycenaean fortifications, highways, dams and canals. Studies in Mediterranean Archaeology 133: 1-254.

Thomas, N. 2004. The early Mycenaean Lion up to date. Hesperia Supplements 33: 161-206. Disponível em: <https://bit.ly/2G0wd9j>. Acesso em: 27/02/2020.

Trigger, B. 1990. Monumental architecture: a thermodynamic explanation of symbolic behaviour. World Archaeology 22: 119-132. Disponível em: <https://bit.ly/3aVXPHJ>. Acesso em: 27/02/2020. 